SCIENTIFIC ORGANIZING COMMITTEE

\begin{tabular}{|c|c|c|}
\hline Chairman : & J. & Audouze, France \\
\hline Co-Chairman : & A. & Szalay, Hungary \\
\hline Members : & $\begin{array}{l}\text { N. } \\
\text { J. } \\
\text { K. } \\
\text { J. } \\
\text { J.P. } \\
\text { M. } \\
\text { E.E. } \\
\text { H. } \\
\text { K. } \\
\text { G. } \\
\text { J. } \\
\text { Y.B. }\end{array}$ & $\begin{array}{l}\text { Bahcall, USA } \\
\text { Einasto, USSR } \\
\text { Kellermann, USA } \\
\text { Oort, The Netherlands } \\
\text { Ostriker, USA } \\
\text { Rees, England } \\
\text { Salpeter, USA } \\
\text { Sato, Japan } \\
\text { Sato, Japan } \\
\text { Setti, Italy } \\
\text { Silk, USA } \\
\text { Zeldovich, USSR }\end{array}$ \\
\hline
\end{tabular}

\title{
LOCAL ORGANIZING COMMITTEE
}

$\begin{array}{ll}\text { Chairman : } & \text { G. } \quad \text { Marx } \\ \text { Co-Chairman : } & \text { A. Szalay } \\ \text { Members : } & \text { L. Balazs } \\ & \text { B. Lukacs } \\ & \text { J. Papp } \\ \text { Executive Secretaries : } & \text { M.C. Pelletan } \\ & \text { Z.S. Szabo. }\end{array}$

